\title{
Triangulation-based 3D surveying borescope
}

Pulwer, S., Steglich, P., Villringer, C., Bauer, J., Burger, M., et al.

S. Pulwer, P. Steglich, C. Villringer, J. Bauer, M. Burger, M. Franz, K. Grieshober, F. Wirth, J. Blondeau, J. Rautenberg, S. Mouti, S. Schrader, "Triangulation-based 3D surveying borescope," Proc. SPIE 9890, Optical Micro- and Nanometrology VI, 989009 (26 April 2016); doi:

10.1117/12.2225203

SPIE. Event: SPIE Photonics Europe, 2016, Brussels, Belgium 


\title{
Triangulation-based 3D surveying borescope
}

\author{
S. Pulwer*a,b P. Steglich ${ }^{\mathrm{a}, \mathrm{b}}$, C. Villringer ${ }^{\mathrm{a}, \mathrm{b}}$, J. Bauer $^{\mathrm{a}}$, M. Burger ${ }^{\mathrm{a}}$, M. Franz ${ }^{\mathrm{c}}$, K. Grieshober $^{\mathrm{c}}$, \\ F. Wirth ${ }^{\mathrm{d}}$, J. Blondeau ${ }^{\mathrm{e}}$, J. Rautenberg ${ }^{\mathrm{f}}$, S. Mouti ${ }^{\mathrm{g}}$, S. Schrader ${ }^{\mathrm{a}}$ \\ aTechnical University of Applied Sciences Wildau, Hochschulring 1, Wildau 15745, Germany; \\ ${ }^{b}$ University of Rome Tor Vergata, Via Orazio Raimondo 18, 00133 Rome, Italy; \\ 'SCHÖLLY FIBEROPTIC GMBH, Robert-Bosch-Str. 1- 3 Denzlingen 79211, Germany; \\ dSCHÖLLY MICRO OPTICS GMBH, An der Amtmannsmühle 11, Biebertal 35444, Germany; \\ 5 5micron GmbH, Rudower Chaussee 29, Berlin 12189, Germany;

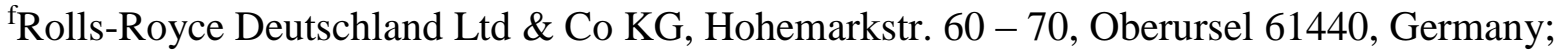 \\ ${ }^{g}$ Rolls-Royce Deutschland Ltd \& Co KG, Eschenweg 11, OT Dahlewitz, Blankenfelde-Mahlow \\ 15827 , Germany
}

\begin{abstract}
In this work, a measurement concept based on triangulation was developed for borescopic 3D-surveying of surface defects. The integration of such measurement system into a borescope environment requires excellent space utilization. The triangulation angle, the projected pattern, the numerical apertures of the optical system, and the viewing angle were calculated using partial coherence imaging and geometric optical raytracing methods. Additionally, optical aberrations and defocus were considered by the integration of Zernike polynomial coefficients. The measurement system is able to measure objects with a size of $50 \mu \mathrm{m}$ in all dimensions with an accuracy of $\pm 5 \mu \mathrm{m}$. To manage the issue of a low depth of field while using an optical high resolution system, a wavelength dependent aperture was integrated. Thereby, we are able to control depth of field and resolution of the optical system and can use the borescope in measurement mode with high resolution and low depth of field or in inspection mode with low resolution and higher depth of field. First measurements of a demonstrator system are in good agreement with our simulations.
\end{abstract}

Keywords: Borescope 3D Measurement, Triangulation, Lens Design, Calibration, Defect

\section{INTRODUCTION}

The development of a miniaturized borescopic measurement technique for the inspection of microscopic defects is an important task in many technical areas and in the field of medicine. Modern borescopes are based on imaging sensors with related optics placed in the tip of the borescope. This principle offers mechanical flexibility and a high optical resolution [1]. On the other hand, it is a new challenge in the area of optic design and mechanical layout. To integrate a 3D measurement technique in a borescope, it is necessary to design a system which efficiently utilize the limited space and to integrate a reasonable optic to measure with high precision. Therefore, we developed a 3D measurement borescope based on triangulation, which contains two individual optical systems, the imaging system with optics and image sensor as well as the projector with optics and illumination system. To generate the periodical pattern, a grid is projected with different spatial frequencies to the object. The image, captured by the imaging system under a certain triangulation angle contains depth and lateral information of the object.

*pulwer@th-wildau.de; phone: +49 3375508771; www.th-wildau.de/photonik

Optical Micro- and Nanometrology VI, edited by Christophe Gorecki, Anand Krishna Asundi, Wolfgang Osten, Proc. of SPIE Vol. 9890, 989009 - @ 2016 SPIE · CCC code: 0277-786X/16/\$18 · doi: 10.1117/12.2225203, 


\section{DEVELOPMENT OF THE BORESCOPIC 3D MEASUREMENT SYSTEM}

Important parameter for the pattern projection, triangulation condition and imaging system were calculated based on partial coherence theory by Hopkins [2,3] and geometric-optical raytracing method [4]. These simulations illustrated in figure 1 can introduce defocus and aberrations on the pupil function of the projection $\mathrm{P}_{\mathrm{S}}(\mathrm{ps}, \mathrm{qs})$ and imaging system $\mathrm{P}(\mathrm{p}, \mathrm{q})$ by integrating Zernike polynomial coefficients and contain lateral information of the lightsource $\mathrm{I}\left(\mathrm{p}_{0}, \mathrm{q}_{0}\right)$ to implement the degree of coherence. $[5,6]$

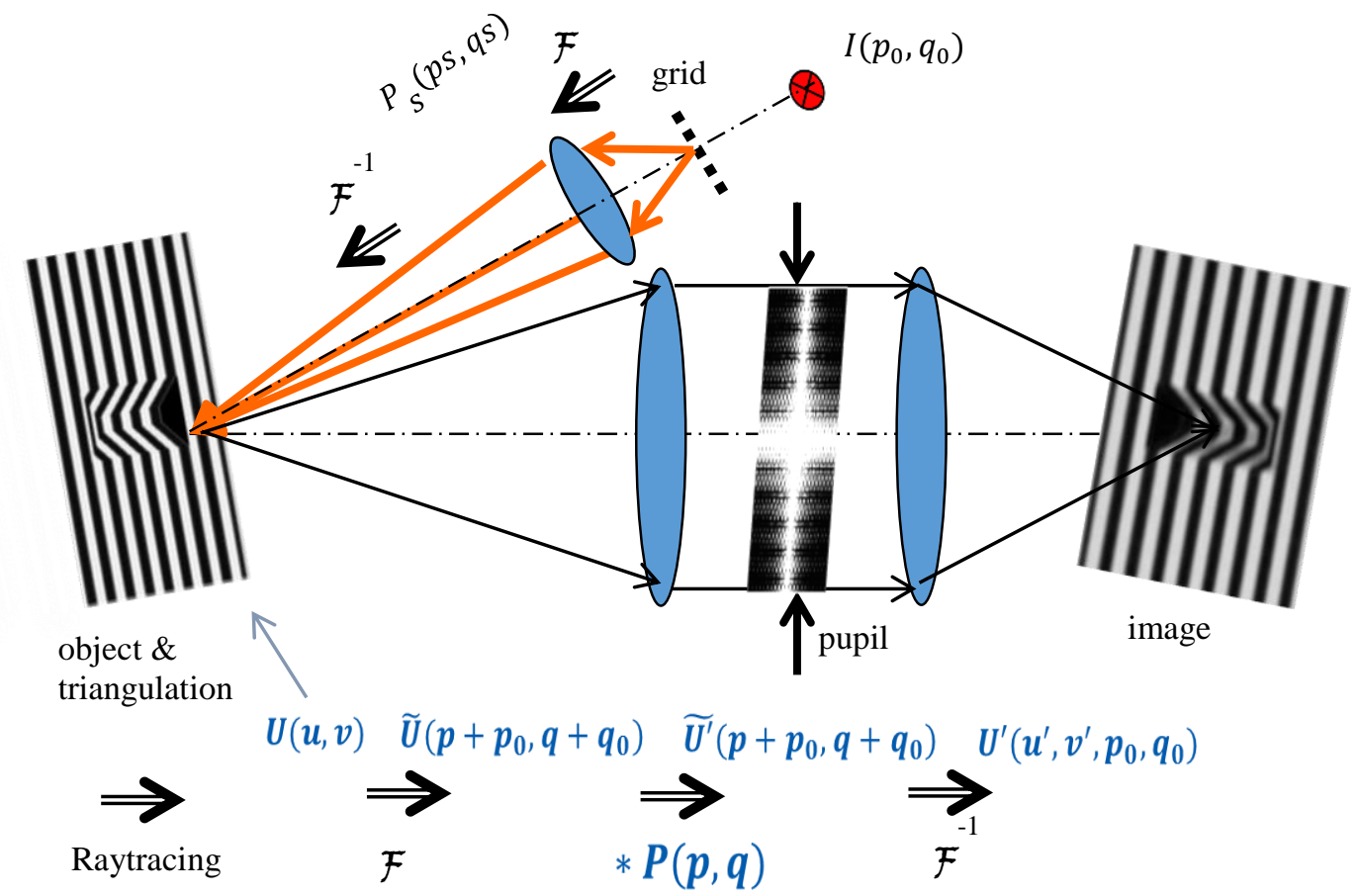

Figure 1. Illustration of the simulation of the fringe projection method, including partial coherence theory $[2,3]$.

The goal was to realize a measurement system, which is able to measure defects with different sizes and shapes. For this, we had to consider the accessibility in the machine. As a result, the outer diameter of the borescopic system was limited to $6 \mathrm{~mm}$ and $15 \mathrm{~mm}$ in length. The spatial frequency related to the pattern projected on the object is connected to the required resolution of $50 \mu \mathrm{m} \pm 5 \mu \mathrm{m}$. For the simulation, we investigated the influence of different grid pitches and triangulation angles on different defect sizes. First we introduced defects with size of (50x50x50) $\mu \mathrm{m}$ and (50x50x150) $\mu \mathrm{m}$ and grid pitches of $20 \mu \mathrm{m}, 30 \mu \mathrm{m}$ and $40 \mu \mathrm{m}$. The optical systems were simulated with variable numerical aperture between 0.01 and 0.1 and a triangulation angle between $10^{\circ}$ and $30^{\circ}$.

For the (50x50x150) $\mu \mathrm{m}$ defect, all grid pitches and triangulation angle combinations show good results with a numerical aperture (NA) of 0.06 . This can be explained by the limited depth of focus for higher NA and limited optical resolution for lower NA [4]. The smaller defect $(50 \times 50 \times 50) \mu \mathrm{m}$, which is similar to the smallest to detectable detail, results in an ambiguous grid offset for certain combinations of triangulation angles and grid pitches. These combinations implicate skips in the grid, which produces not detectable areas of the defect. Hence, we used a projected grid with two different pitches of $30 \mu \mathrm{m}$ and $65 \mu \mathrm{m}$ in the projection plane. 


\subsection{Opto-mechanical concept}

The first concept considers the results of the simulations and the opto-mechanical design rules. Therefore, predesigns of the optical systems were combined with CAD constructions. With this concept, we determined the distance between the optical axis of the camera system and projection system to $2.5 \mathrm{~mm}$, related to a working distance of $4 \mathrm{~mm}$ to reach a triangulation angle as demanded. Further, we analysed the mechanical constraints which are strongly connected with fabrication tolerances and integrated mounts for the optical components. Figure 2 shows the combination of the CAD mechanic setup and raytracing data. Additionally, we designed the grid structure including a reference mark at the centre and grid pitches in the object plan of $5.45 \mu \mathrm{m}$ and $11.8 \mu \mathrm{m}$. A silica substrate with structured chrome coating was used in order to produce the grid. To guarantee good light conditions at the area of interest we integrated on both sides of the borescope fibre bundles witch are coupled to a white light source.

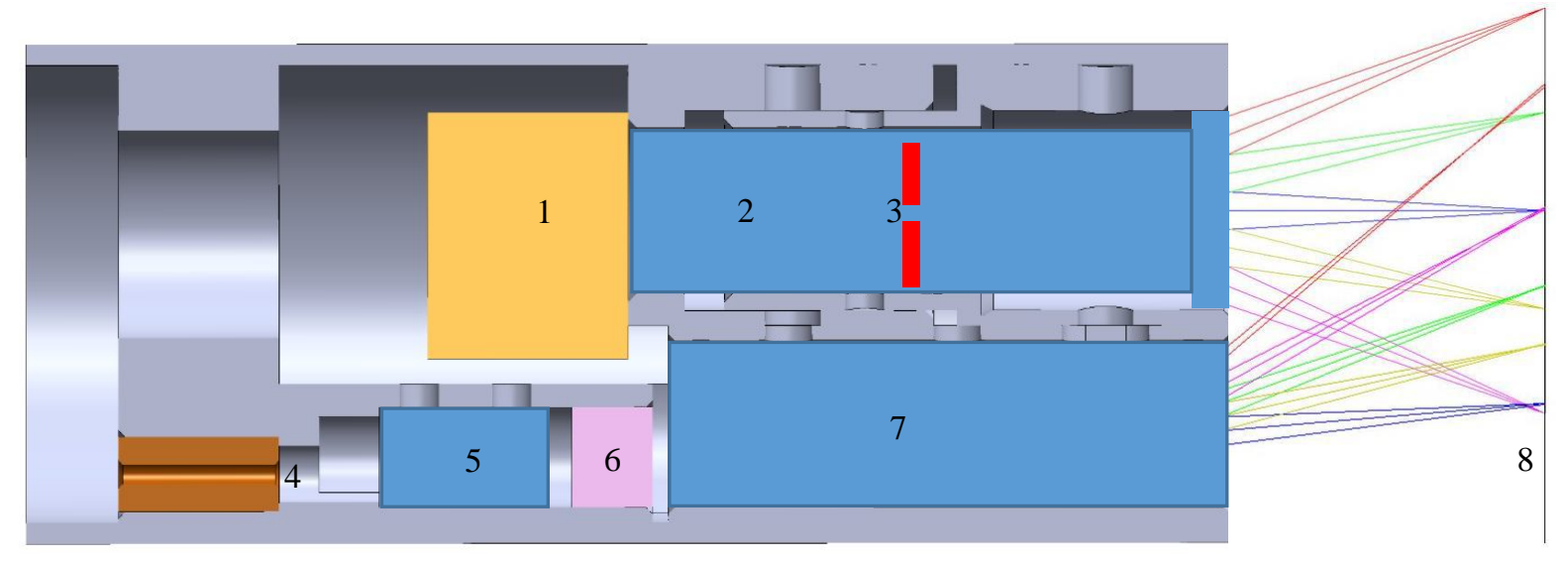

Figure 2. CAD model with raytracing data, including following components: 1: image sensor with camera board, 2: imaging lens system, 3: line filter 4: light source, 5: condenser, 6: grid with substrate; 7: projector lens system; 8: object to be measured.

\subsection{Imaging system}

The camera is based on a 1/9" CMOS image sensor with a resolution of $1280 x 720$ pixels in a 16:9 format. Additionally, we designed the lens system for the camera, resulting in a lens with $\pm 20^{\circ}$ viewing angle, $\mathrm{NA}=0.054$ and effective focal length of $1.56 \mathrm{~mm}$. It is composed of seven optical elements with lens diameter of $2 \mathrm{~mm}$. The system was optimized for the peak wavelength of $\lambda=633 \mathrm{~nm}$ without corrections for chromatically aberrations. At the pupil position, a line filter with a centre wavelength of $\lambda=633 \mathrm{~nm}$ and full width half maximum of $10 \mathrm{~nm}$ is positioned. Moreover, a whole with a diameter of $200 \mu \mathrm{m}$ is added into the filter. Thus, we could achieve a wavelength dependent numerical aperture, which is adjustable by changing the wavelength of the incoming light. This technology enables to control depth of field and optical resolution of the optical system. Thereby, the borescope can be used in measurement mode with high optical resolution and low depth of field or in inspection mode with low resolution and higher depth of field. The average modulation transfer function (MTF) of sagittal and tangential components (figure 3) shows analysable contrast of 0.2 for spatial frequencies of $250 \mathrm{lp} / \mathrm{mm}$ for the whole field for. In contrast, the inspection mode lacks of resolution and resolves $60 \mathrm{lp} / \mathrm{mm}$ with reasonable contrast [7].

Furthermore, we analysed the behaviour of both modes by calculating the depth of field at a fixed spatial frequency of $25 \mathrm{lp} / \mathrm{mm}$ displayed in figure 4 . It proves that the system is capable to adjust the depth of field. This low spatial frequency represents the case, when the borescopic system is used to inspect unknown surfaces and to navigate in unknown surroundings. In practise, the user can control both modes by selecting the white light source for inspection mode and the red light source for measuring mode. 


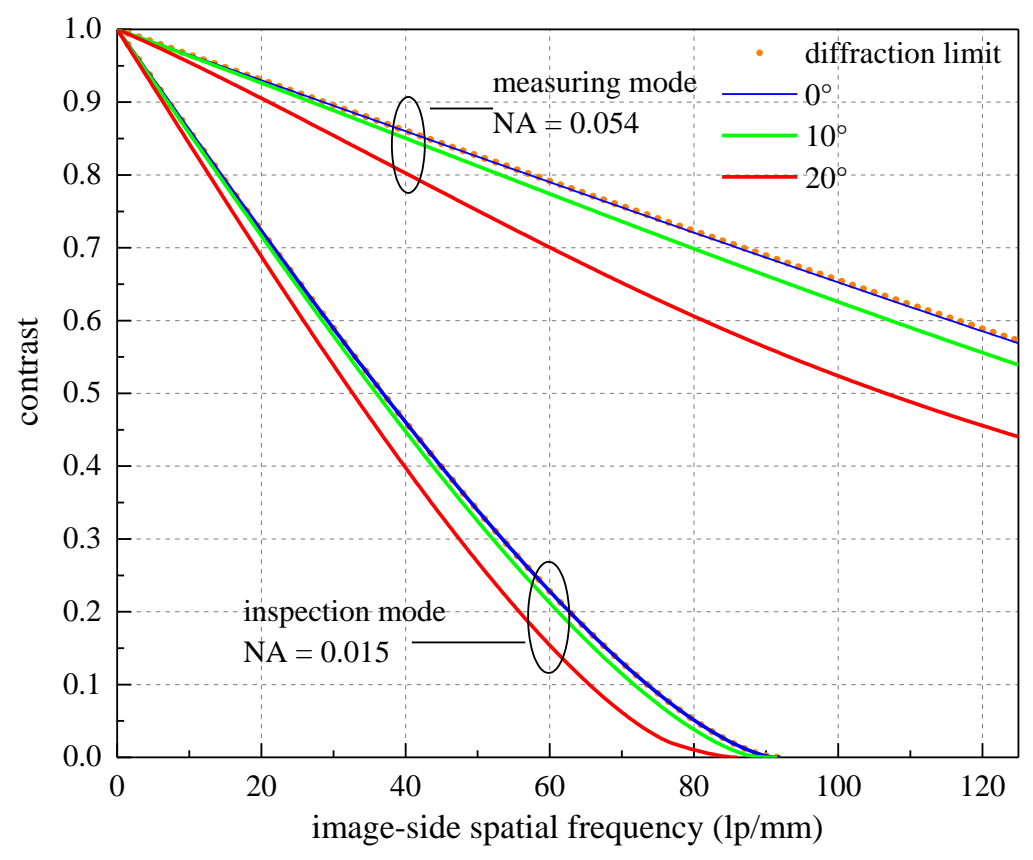

Figure 3. Calculated monochromatic average MTF at $\lambda=633 \mathrm{~nm}$ for different viewing angles of the imaging system for inspection mode and measuring mode.

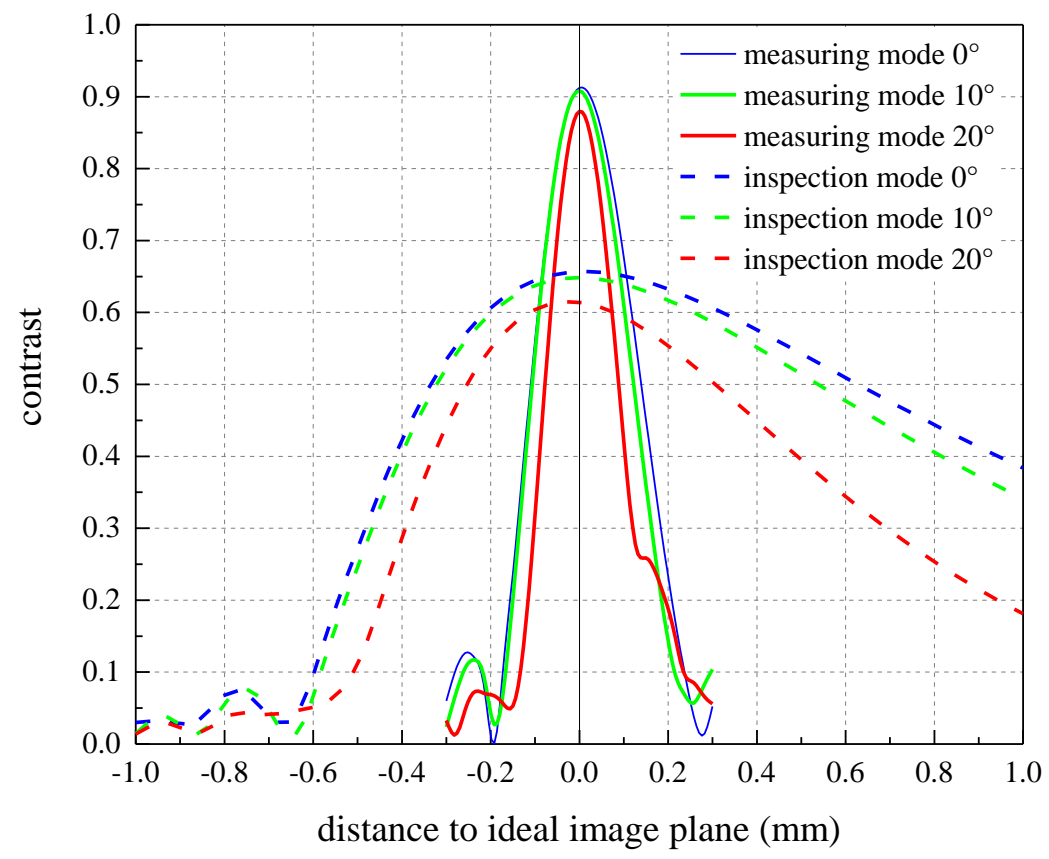

Figure 4. Calculation of monochromatic average MTF at $\lambda=633 \mathrm{~nm}$ and fixed spatial frequency of $25 \mathrm{lp} / \mathrm{mm}$ for different viewing angles in inspection mode and measurement mode with respect to the image plane. 


\subsection{Projection system}

To realize the triangulation angle between camera and projector without tilting one system an off - axis projection system was developed. Therefore, the optical axis of the projected object with respect to the optical axis of the projection lens system was decentred. To decrease vignetting effects caused by the limited lens diameter, we introduced a third optical axis to the monochromatic light source with an effective output power of $2.5 \mathrm{~mW}$. Moreover, we used a LED coupled multi-mode fibre with $200 \mu \mathrm{m}$ core diameter and NA $=0.22$. The whole system was designed according to Köhler illumination and has a NA $=0.04$. It contains ten optical elements with diameter of $2 \mathrm{~mm}$ for the projection lens and $1.2 \mathrm{~mm}$ for the illumination system including the grid.

\section{RESULTS}

In order to obtain an impression of the capability of the borescope in general, we used a flat anodized aluminium plate. Figure 5 shows an image taken with the borescopic system at a working distance of $4 \mathrm{~mm}$ while the plate was vibrating in lateral plane.

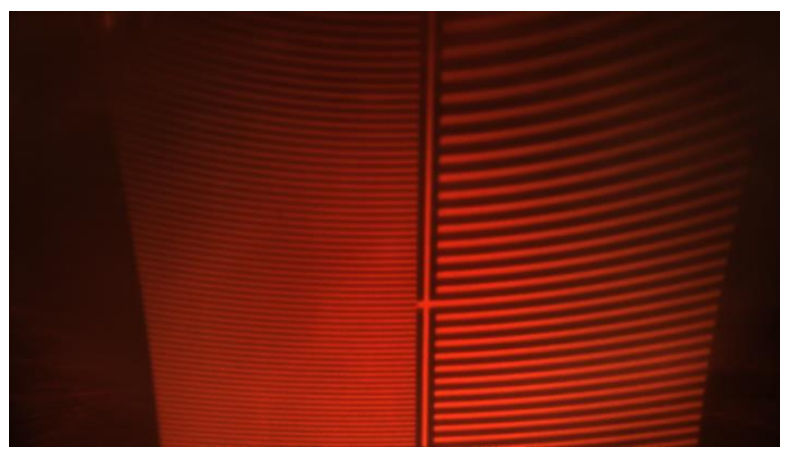

Figure 5. Image of a flat surface taken with the borescopic system with lateral integration method.

With this method we are able to measure the optical performance of the system with no influence of the substrate caused by the surface roughness [8]. A visible distortion mainly caused by the off-axis projection system can be observed. MTF analyse reveals contrast values of 0.3 for the high spatial frequency grid pitch and 0.6 for the low spatial frequency grid pitch, measured next to the reference mark (centre). In addition to that, we calibrated the measurement system by using calibration targets with different peak-to-valley (PV) values. Figure 6 shows a target with PV value of $40 \mu \mathrm{m}$, which gives a reasonable example of the sensitivity of this $3 \mathrm{D}$ measurement borescope. The pattern transformation due to the surface structure is clearly recognizable.

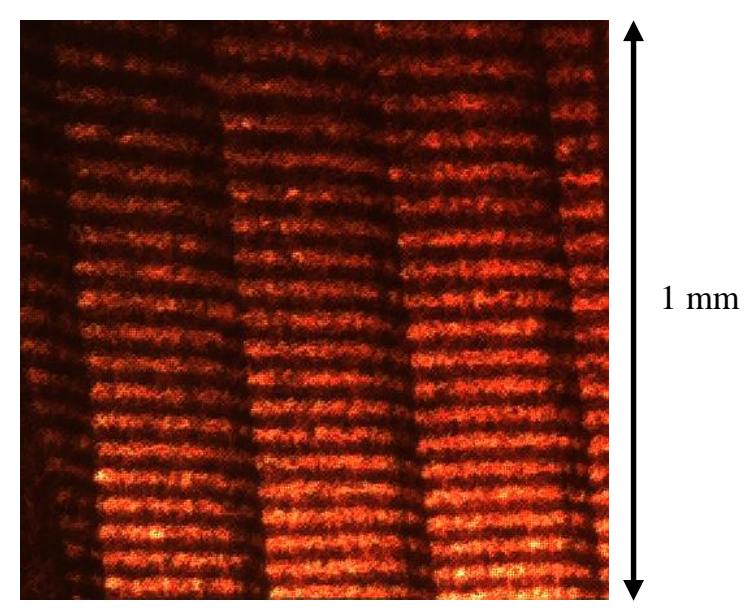

Figure 6. Image of a calibration target with peak-to-valley value of $40 \mu \mathrm{m}$ taken with the borescopic measurement system. 


\section{CONCLUSION}

With the proposed measurement system, built up as a borescopic system with flexible properties, we are capable of performing high precision measurements of difficult to access parts of machines. The combination of CAD and raytrace data analyse were used for best utilize the limited space available. We integrated two individual optics with different

functions. The imaging system shows decent optical performance and the adjustable depth of field gives the user the opportunity to choose between resolution and depth of field. However, the next step is to improve the setup of the optical filter, used as the aperture. Therefore we will integrate mask coatings on the filter to avoid scattering light. Furthermore we will extend the borescopic system with different viewing angles.

\section{ACKNOWLEDGEMENTS}

We would like to thank the Federal Ministry for Economic Affairs and Energy (BMWi) for funding this project within the 5. Luftfahrtforschungsprogramm (LuFo V).

\section{REFERENCES}

[1] SCHÖLLY FIBEROPTIC GMBH, "EZYSCOPE FAMILY MODERN VIDEOSCOPE SOLUTIONS", April 2015, http://www.schoelly.de/files/9414/3945/6056/MPB210-000-1504-01.pdf (07 March 2016).

[2] Hopkins, H. H., “On the Diffraction Theory of Optical Images”, The Royal Society, A 217 (1953).

[3] Hopkins, H. H., et al. "The Concept of Partial Coherence in Optics - Volume 208", The Royal Society (1951).

[4] Singer, W., Totzek , M. and Gross, H., [Handbook of Optical Systems - Volume 2: Physical Image Formation], WILEY-VCH Verlag (2005).

[5] Born, M. and Wolf, E., [Principles of Optics], Oxford: Pergamon (1970).

[6] Richter, W. et al., "Theorie der Abbildung und Grundlagen von Lens Design", Lehrunterlagen - TU Ilmenau (2008).

[7] Haferkorn, H., [Bewertung optischer Systeme], VEB Deutscher Verlag der Wissenschaften (1986).

[8] El-Ghandoor, H. et al., "Analysis of Surface Roughness Using Laser Optical Imaging Techniques", Journal of Materials Science and Engineering B 2 (2012). 